\title{
Future Heatwaves in NSW from the NARCliM ensemble
}

\author{
$\underline{\text { J.P. Evans }}^{\text {a }}$, D. Argueso ${ }^{\text {b }}$ and A. Di Luca ${ }^{\text {a }}$ \\ ${ }^{a}$ Climate Change Research Centre and ARC Centre of Excellence for Climate System Science, School of \\ Biological, Earth and Environmental Sciences, University of New South Wales, Sydney, NSW \\ ${ }^{b}$ University of Balearic Islands, Palma, Spain \\ Email: Jason.evans@unsw.edu.au
}

\begin{abstract}
NARCliM (NSW/ACT Regional Climate Modelling project) is a regional climate modeling project for the Australian area. It provides a comprehensive dynamically downscaled climate dataset for the CORDEX-AustralAsia region at $50 \mathrm{~km}$ resolution, with a finer $10 \mathrm{~km}$ resolution across South-East Australia. NARCliM data is being used by the NSW and ACT governments to design their climate change adaptation plans. Data is available through the AdaptNSW website (http://climatechange.environment.nsw.gov.au/).

NARCliM uses WRFv3.3 regional climate model (RCM) to perform an ensemble of simulations for the present and the projected future climate. WRF is run in three different model configurations (different combinations of physical parametrizations) that have been shown to perform well in South-East Australia and were chosen based on performance and independence. These three RCMs are simulating three different periods: 1990-2009, 2020-2040 and 2060-2080. Four different GCMs (MIROC-medres 3.2, ECHAM5, CGCM 3.1 and CSIRO mk3.0) from CMIP3 provide initial and boundary conditions for the WRF simulations. These GCMs were chosen through a process that considered model performance, independence and diversity in projected future changes. This GCM-RCM matrix gives an ensemble of 12 simulations for each period.

Heatwaves are here defined using the Excess Heat Factor metric. Its characteristics, including duration, frequency and intensity, are examined. Compared to observations, the NARCliM ensemble displays a good ability to simulate heatwaves across NSW with almost all present-day biases being non-significant. By 2070, robust increases in heatwave frequency, duration and peak amplitudes are found across NSW and the ACT. Western NSW is projected to have the most significant increases in peak amplitude. Most of NSW is projected to experience about 20 more heatwave-days a year by 2070 compared to the present. In many locations this is more than a doubling of the current number of heatwave days.
\end{abstract}

Keywords: $\quad$ NARCliM, Regional climate downscaling, heatwaves 


\section{INTRODUCTION}

Heatwaves represent a significant hazard in Australia for both humans and the environment and have been responsible for more deaths than any other natural hazard, including bushfires, storms, tropical cyclones and floods (Coates et al., 2014). The Bureau of Meteorology employs the Excess Heat Factor (EHF) definition for a heatwave (Nairn and Fawcett, 2014). The EHF is a measure of heatwave intensity that incorporates two measures of excess heat. In this way, the EHF takes into account the expectation that people acclimatise to their local, recent climate (at least to some extent), with respect to its temperature variation across latitude and throughout the year, but may not be prepared for a sudden rise in temperature above that of the recent past. The EHF has previously been used to study the impacts of extreme heat events on human health. Langlois et al. (2013) examined the 2009 south-east Australian heatwave event by using the EHF, concluding that peak morbidity and mortality rates in the region were experienced immediately after the highest EHF value. The EHF can provide a universal definition for heatwaves, and thus is a powerful metric for projecting heat-related morbidity and mortality. It is also incorporated into the framework recommended by Perkins and Alexander (2012). They show that the frequency, intensity and duration of heatwaves have each increased over Australia since the $1950 \mathrm{~s}$, but particularly since the $1970 \mathrm{~s}$.

In NSW (Figure 1) specifically, trends in the intensity of EHF-positive events, annual maxima EHF and the severity of EHF events have increased between 1958 and 2011 (Nairn and Fawcett, 2014), although, interestingly, there has been a slight decrease in all of these metrics east of the Great Dividing Range. Over a similar period, across NSW and the ACT trends tend to show up more strongly and statistically significantly in EHF measures compared with other heatwave measures (such as days when maximum temperature is above the 90th percentile) using the Perkins and Alexander (2012) framework; broadly speaking duration or frequency measures tend to show stronger trends that amplitude measures.

This study presents heatwave characteristics derived from the Collaboration for Australian Weather and Climate Research (CAWCR) Excess Heat Factor (EHF) metric, their biases, and projected future changes for the state of New South Wales and the Australian Capital Territory. These results are based on simulations performed as part of the NSW/ACT Regional Climate Modelling (NARCliM) project.

\section{METHODS}

\subsection{Gridded Observations}

The Australian Water Availability Project (AWAP) produced a daily gridded dataset at a spatial resolution of $0.05^{\circ}$ by $0.05^{\circ}$ (approximately $5 \mathrm{~km}$ by $5 \mathrm{~km}$ ) covering Australia (Jones et al., 2009). It was constructed by using an anomaly-based approach to interpolate information from meteorological stations onto a regular grid for a range of variables, including daily maximum and minimum temperature. The period considered here extends from 1911-2013. The number of temperature stations used to generate AWAP varies through time, but during most of the NARCliM reanalysis period (1950-2009) it ranges from 200 to 800 stations. Substantially fewer stations were available for the years before 1956, and in some cases the number of stations used decreases to $\sim 100$.

\subsection{NARCliM Climate Projections}

The NARCliM project is designed to create regional-scale climate projections for use in climate change impacts and adaptation studies, and ultimately to inform climate change policymaking (Evans et al., 2014). Details on NARCliM can be found here (http://www.ccrc.unsw.edu.au/NARCliM/) and on the AdaptNSW website.

In NARCliM three RCMs are used to downscale four GCMs for three 20-year time slices (1990-2009 or 'present'; 20202039 or 'near future'; 2060-2079 or 'far future'). For future projections, the Special Report on Emissions Scenario (SRES) A2 emission scenario is used. A careful choice of both RCMs and GCMs was made to ensure all models performed adequately, were independent (Evans et al., 2013) and the GCMs spanned the future change range of temperature and precipitation. The GCMs chosen are the MIROC3.2, ECHAM5, CCCMA3.1 and CSIRO-MK3.0. The chosen

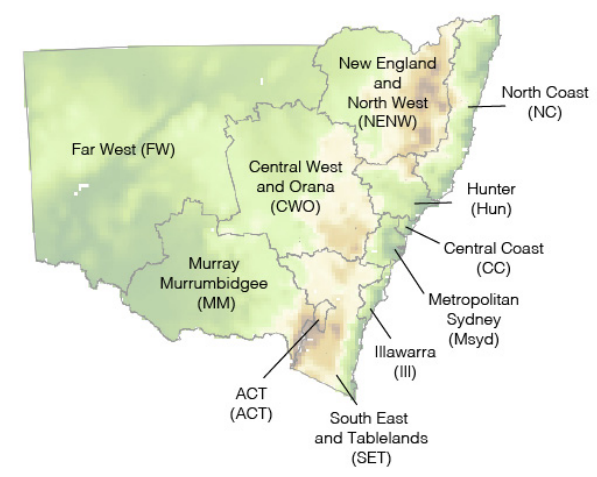

Figure 1. Names of state planning regions and abbreviations in NSW and the ACT. 
RCMs are versions of the WRF model with different parameterizations of planetary boundary layer, surface layer, cumulus physics, microphysics and radiation.

\subsection{Excess Heat Factor (EHF)}

The EHF is the index chosen by the Bureau of Meteorology to operationally define and monitor heatwaves. The underlying idea of EHF is to estimate the excess heat accumulated over 3 consecutive days through two indices. The first index is a measure of acclimatisation $\left(\mathrm{EHI}_{\mathrm{accl}}\right)$ and compares the 3-day average temperature with the previous 30-day average temperature:

$\mathrm{EHI}_{\mathrm{accl}}=\left(\mathrm{T}_{\mathrm{i}}+\mathrm{T}_{\mathrm{i}-1}+\mathrm{T}_{\mathrm{i}-2}\right) / 3-\left(\mathrm{T}_{\mathrm{i}-3}+\cdots+\mathrm{T}_{\mathrm{i}-32}\right) / 30$

where $T_{i}$ is the daily mean temperature of day $i$, calculated as the mean between the daily maximum $\left(t_{\max }\right)$ and minimum $\left(t_{\min }\right)$ temperatures on a daily 9 am to 9 am cycle, such that $t_{\min }$ occurs after $t_{\max }$ for day i. The second index is denoted as 'significance' $\left(\mathrm{EHI}_{\text {sig }}\right)$ and determines how extreme the temperature conditions are by comparing the 3-day average temperature with the 95th percentile of the daily mean temperature calculated over the period of reference (base period) and is denoted by $\mathrm{T}_{95}$ :

$\mathrm{EHI}_{\text {sig }}=\left(\mathrm{T}_{\mathrm{i}}+\mathrm{T}_{\mathrm{i}-1}+\mathrm{T}_{\mathrm{i}-2}\right) / 3-\mathrm{T}_{95}$

The original definition used the period 1961-1990 to calculate the percentile, but here we use the 1990-2009 period in order to match the NARCliM present climate period. It is important to note that future climate heatwaves are obtained by using the same reference period (1990-2009) to calculate the percentiles, and thus future changes can be directly interpreted with respect to recent climate conditions.

These two indices are combined to compute the final EHF in the following equation:

$\mathrm{EHF}=\max \left(1, \mathrm{EHI}_{\mathrm{accl}}\right) \times \mathrm{EHI}_{\mathrm{sig}}$

$\mathrm{EHF}$ has ${ }^{\circ} \mathrm{C}^{2}$ units because it is the product of two temperature anomalies. A heatwave is identified when EHF takes values larger than 1 over 3 or more consecutive days. This ensures that the conditions are extreme and that they persist long enough for the event to be considered a heatwave. Once heatwave events are identified, EHF provides us with information to quantify multiple heatwave characteristics, such as their intensity, frequency and duration. Here we analyse the following metrics:

- HWAt (heatwave amplitude): amplitude of the hottest day in the hottest heatwave event in a year; the maximum EHF of the heatwave with the highest average EHF in a year $\left({ }^{\circ} \mathrm{C}^{2}\right)$. Here we take the corresponding 3-day mean temperature in ${ }^{\circ} \mathrm{C}$.

- HWF (heatwave frequency): number of heatwave days expressed as the percentage of days in a year

- HWD (heatwave duration): duration of the longest heatwave in a year (days).

\section{RESULTS}

First the observed present day (1990-2010) heatwaves and observed heatwave trends (1911-2013) are presented. Then the NARCliM representation of present day heatwaves is evaluated against the observations. This is followed by the future changes in heatwave characteristics.

\subsection{Observed Heatwaves}

Figure 2 shows the present-day (1990-2009) climatologies for the heatwave characteristics. The temperature of the maximum heatwave (HWAt) has a spatial pattern that is strongly linked to the topography and distance to the ocean. The frequency of heatwave days (HWF) is fairly uniform at around $3 \%$ of days $(\sim 11$ days per year). On average, the longest heatwave duration (HWD) tends to be larger in the centre of the state, where the
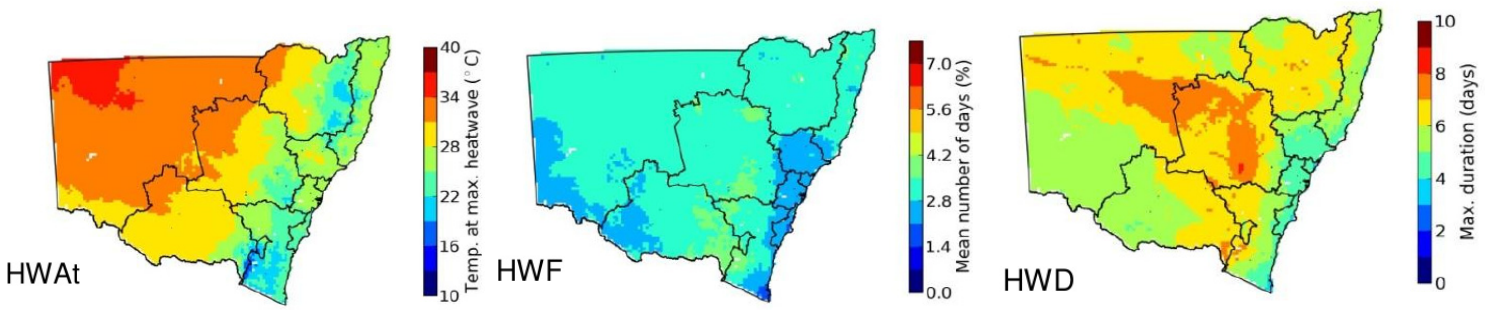

Figure 2. Present-day climate (1990-2009) heatwave indices obtained from AWAP observations. 

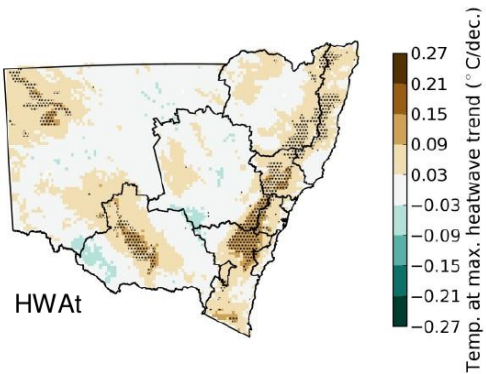
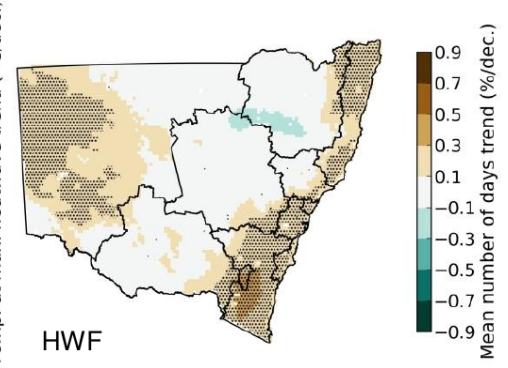

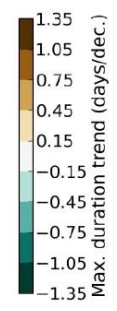

Figure 3. Trends in heatwave metrics over the full AWAP record. Stippling indicates that the trends are significant at the $5 \%$ level. Trends and significance are calculated by using the method described by

Hartmann et al. [37].

longest heatwave in a year typically lasts 7 to 8 days. This contrasts with values in the south and Central Coast, which stay below 5 days.

Figure 3 shows the trends in heatwave characteristics from 1911 to 2013. These trends are estimated using the linear trend model employed in the Intergovernmental Panel on Climate Change (IPCC) Fifth Assessment Report (IPCC AR5 [40]). Trend slopes in this model are the same as those in a standard ordinary least squares regression model but allow for first-order autocorrelation in the residuals. Statistical significance is tested at the 5\% level $(\mathrm{P}<0.05)$, also with the IPCC AR5 method (IPCC, 2013). For HWAt, most of the statistically significant increasing trends occur along the Great Dividing Range, with increases of up $1.4^{\circ} \mathrm{C}$ over the record in the hottest part of the heatwave. Trends are statistically significantly increasing along the eastern seaboard for the duration and frequency characteristics and in some western parts of NSW and are up to $0.5 \%$ per decade in the south-east of the state in terms of heatwave frequency (HWF - equivalent to about 14 additional heatwave days over the record in that region). Where trends are increasing, the results suggest that there are between about 4 and 11 more heatwave days in a year now than there were at the beginning of the 20th century.

\subsection{NARCliM Biases in Present Day}

Figure 4 shows the difference between simulated heatwave characteristics from the NARCliM ensemble and AWAP observations. Biases are defined as the difference between the climatological average from the NARCliM ensemble and the AWAP observations for the period 1990-2009. The coloured contours provide information on differences between the NARCliM ensemble mean and the AWAP data, whereas the stippling indicates the level of model agreement. The NARCliM ensemble-mean biases are separated into three categories, namely (a) fewer than half of the models show a significant bias (non-significant areas; ensemblemean bias is shown in colour); (b) at least half of the models show a significant bias and at least $80 \%$ of significant models agree on the sign of the bias (significant areas of agreement; stippled with an asterisk ('*') symbol); and (c) at least half of the models show a significant bias but fewer than $80 \%$ of significant models agree on the sign of the bias (significant areas of disagreement; stippled with a forward slash ('/') symbol). Therefore, in non-stippled areas the biases are within the interannual variability; this is the preferred outcome. Also, a lack of forward-slash stippling indicates that, among the models, significant areas of disagreement do not appear to be widespread. For each index, the significance of biases of individual models was estimated with respect to the interannual variability by using Student's t-test at the $5 \%$ significance level $(\mathrm{P}<0.05)$.

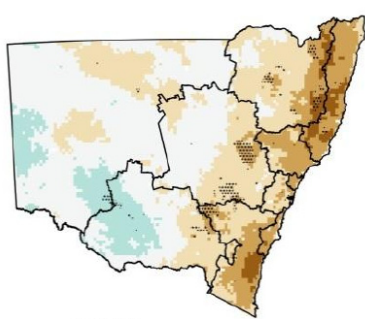

HWAt
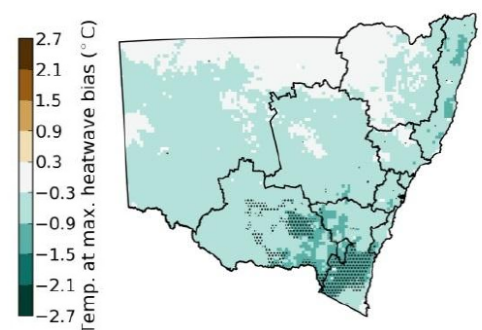

HWF
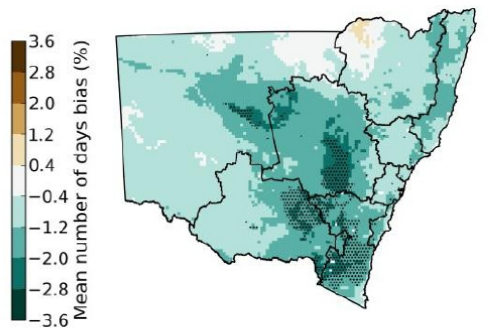

HWD

Figure 4. Bias of each heatwave index between the NARCliM ensemble mean and AWAP observations for present-day climate (1990-2009). Stippling indicates areas where the biases are significant for at least half of the models and at least $80 \%$ of them agree on the sign of the bias 

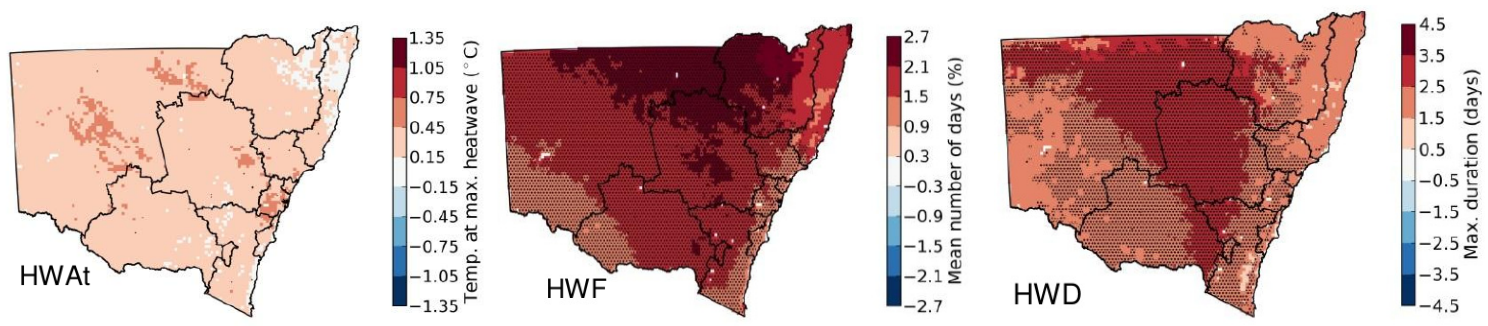

Figure 6. Near-future (2020-2039) projected changes for heatwave indices obtained from the NARCliM with respect to the present-day climate (1990-2009). Stippling indicates areas where future changes are significant for at least half of the models and at least $80 \%$ of them agree on the direction of the change.
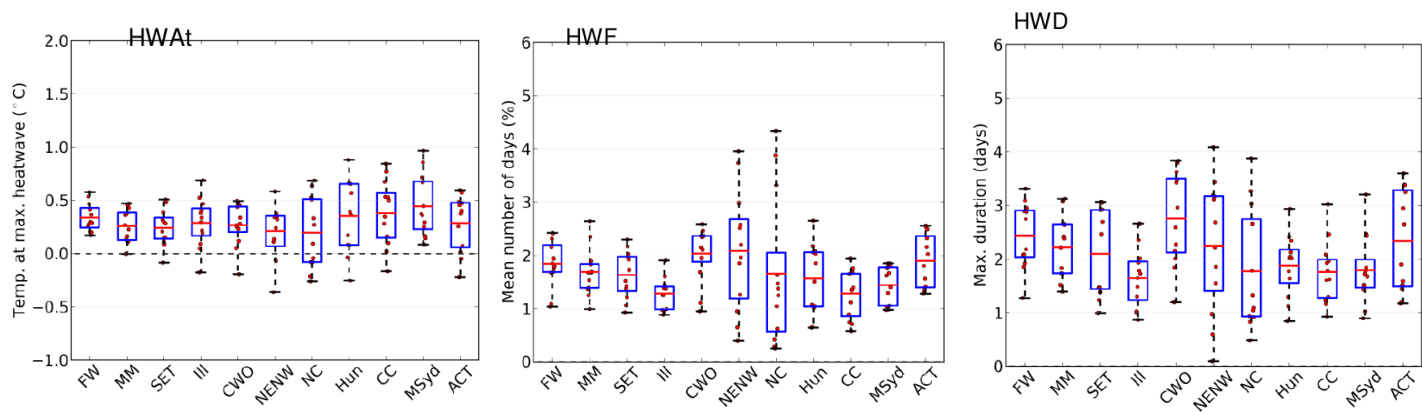

Figure 5. Near-future (2020-2039) projected changes in heatwave indices with respect to present-day climate (1990-2009). The NARCliM ensemble mean change (red line), interquartile range of changes (blue box) and range (whiskers) of changes are represented for each heatwave index and region. Red dots represent values from individual members.

HWAt is also slightly overestimated along the coast (by 0.5 to $2.5^{\circ} \mathrm{C}$ ) and underestimated over limited areas in the south-west (by -0.5 to $-1.5^{\circ} \mathrm{C}$ ). This compares to cold bias of up to a few degrees in the mean maximum temperature. However, biases are overall within the expected range of variability, with very few exceptions. In terms of the number of heatwave days, NARCliM simulates slightly lower values over most of the state $(0.4 \%$ to $1.2 \%$ fewer heatwave days per year), but the significant biases are confined to areas in the south, where biases are moderately larger (1.2\% to $2.0 \%$ fewer heatwave days per year). NARCliM tends to produce shorter heatwaves over most of the state. The longest yearly heatwaves in NARCliM last, on average, for 0.5 to 2.5 fewer days than in AWAP over large areas of NSW and the ACT. Sectors in the interior and the southern mountains show larger (significant agreeing) biases whereby heatwaves are between 2.5 and 3.5 days shorter in NARCliM than in AWAP.

\subsection{Near Future Changes in Heatwave Characteristics}

Figure 6 illustrates the NARCliM ensemble mean changes for all heatwave indices, as obtained from the difference between climatologies for the periods 2020-2039 and 1990-2009. The coloured contours provide information on near-future changes in the NARCliM ensemble mean, whereas the stippling indicates the level of model agreement. The NARCliM ensemble-mean changes are separated into three categories, namely (a) less than half of the models show a significant change (non-significant areas; ensemble-mean change shown in colour); (b) at least half of the models show a significant change and at least $80 \%$ of the significant models agree on the sign of the change (significant areas of agreement; stippled with an asterisk ('*') symbol); and (c) at least half of the models show a significant change and fewer than $80 \%$ of significant models agree on the sign of the change (significant areas of disagreement; stippled with a forward slash ('/') symbol). Non-stippled areas thus indicate that changes are within the interannual variability. Also, a lack of forward-slash stippling indicates that significant areas of disagreement among the models do not appear to be widespread. For each index, the significance of changes in individual models was estimated with respect to the interannual variability by using Student's t-test at the 5\% significance level $(\mathrm{P}<0.05)$.

In Figure 6 almost the entire region will exhibit changes in HWAt that will not exceed $0.5^{\circ} \mathrm{C}$, with very minor exceptions for HWAt around Sydney and in the interior. On the other hand, the NARCliM results indicate that the frequency (HWF) and duration of heatwaves (HWD) will undergo statistically significant changes with respect to 1990-2009 over most of NSW and the ACT, even for this near future time horizon. In terms of the number of heatwave days (HWF), all regions except the NC and parts of NENW exhibit statistically significant 
changes, although the northern interior would see the largest changes (an increase of $2.1 \%$ to $2.7 \%$ of days, equivalent to $\sim 7.5$ to 10 more heatwave days per year). Similarly, the longest heatwave in a year (HWD) will be 1.5 to 3.5 days longer on average over most regions, with exceptions along the coast and in the southwestern corner. Such changes in the duration of heatwaves are statistically significant over most areas.

Figure 5 shows near-future projected changes (2020-2039 minus 1990-2009) in heatwave indices for each of the regions, including the spread across NARCliM ensemble members. All regions show a similar increase in HWAt (between 0 and $0.5^{\circ} \mathrm{C}$ ) according to the NARCliM ensemble mean. Regions in the centre and near the coast (Hun, CC, and MSyd), together with the ACT, show the largest changes $\left(0.4\right.$ to $\left.0.5^{\circ} \mathrm{C}\right)$. In these regions and NC, NARCliM members show the largest disagreement in projections, whereas the NARCliM simulations show a reduced spread in the western and southern regions.

Frequency and duration of heatwaves are expected to increase in all NARCliM models and regions. The frequency of heatwave days, is projected to increase by from $1.4 \%$ of days in Ill and NC to over $2 \%$ of days in CWO and NENW. However, some models project increases as large as $4 \%$ of days in NENW and NC, showing more uncertainty over these two regions.

The duration of the longest heatwave in a year is projected to increase in all regions. The largest increases occur in CWO (just below 3 days longer), followed by FW and NENW ( 2.5 days longer). NC shows the lowest values, with changes hardly exceeding 1 day, although once again $\mathrm{NC}$ is among the regions with largest spread.

\subsection{Far Future Changes in Heatwave Characteristics}

Figure 7 illustrates the NARCliM ensemble mean changes for all heatwave indices, as obtained from the difference between climatologies for the periods 2060-2079 and 1990-2009. The yearly heatwave peak (HWAt) shows increases over all of NSW, although they appear as statistically significant only over the western regions, with changes ranging between 0.5 and $1.5^{\circ} \mathrm{C}$ over all of NSW. Frequency (HWF) and duration (HWD) of heatwaves will undergo statistically significant changes over all of NSW and the ACT with respect to the present-day period. The mean percentage of heatwave days (HWF) shows a clear north-south gradient, with larger values in the north (between $7 \%$ and $9 \%$ more days of heatwaves per year) and values of about $2 \%$ more days of heatwaves per year in the south-west and south-east of NSW. Far-future changes in the longest
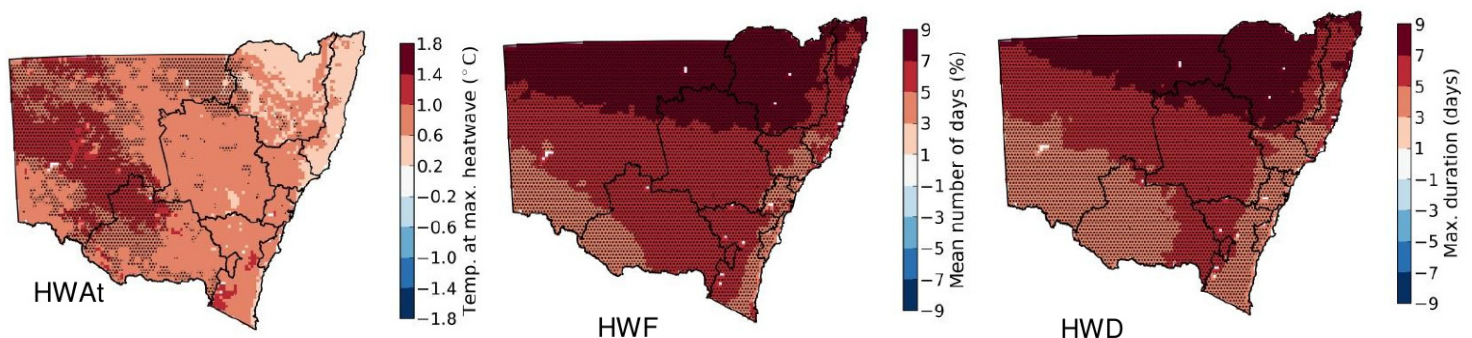

HWD

Figure 7. Far-future (2060-2079) projected changes for heatwave indices, with respect to the present-day climate (1990-2009). Stippling indicates areas where future changes are significant for at least half of the models and at least $80 \%$ of them agree on the direction of the change.
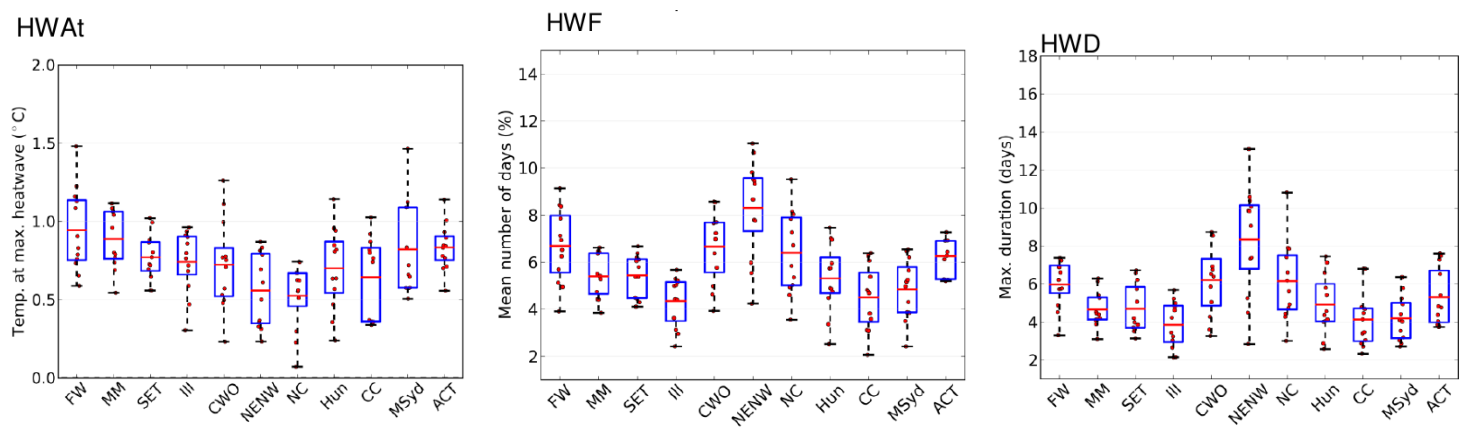

Figure 8. Far-future (2060-2079) projected changes in heatwave indices with respect to present-day climate (1990-2009). The NARCliM ensemble mean change (red line), interquartile range of changes (blue box) and range (whiskers) of changes are represented for each heatwave index and region. Red dots represent values from individual members. 
heatwave in a year (HWD) show a spatial distribution very similar to that of HWF. HWD is expected to be 2 to 14 days longer on average, depending on the region considered. Regions in the north-east (NENW) would experience the largest changes in HWD, whereas the smallest changes are expected to arise in the southern part of NSW.

Figure 8 shows far-future projected changes in heatwave indices for each of the regions, including the spread across NARCliM ensemble members. All NARCliM ensemble members project increasing changes in the yearly maximum intensity of heatwaves (HWAt) for all regions of NSW. The NARCliM ensemble mean increases that vary between 0.5 and $1{ }^{\circ} \mathrm{C}$, with the smallest changes arising over north-eastern regions of NSW. Far-future projections show that the frequency of days (HWF) and duration (HWD) of heatwaves are expected to increase in all NARCliM members and regions. The increase in the mean percentage of heatwave days is between $4 \%$ and $10 \%$ of days compared with present values. The largest changes arise in the north-eastern regions of NSW, whereas the smallest are in Hun and CC. The duration of the longest heatwave also increases in far-future projections, by about 4 days in regions along the coast and by about 8 days in the NENW region.

\section{CONCLUSIONS}

This report has presented heatwave characteristics derived from the CAWCR Excess Heat Factor metric, their biases, and projected future changes for NSW and the ACT. The NARCliM ensemble displays a good ability to simulate heatwaves across NSW and the ACT, with almost all present-day biases being non-significant. NARCliM finds significant increases in heatwave frequency and duration in the near future for much of NSW and the ACT. Although increases in the peak heatwave amplitude are projected, these increases are not significant in the near future. In the far future, robust increases in heatwave frequency, duration and peak amplitudes are found across NSW and the ACT. Western NSW is projected to have the most significant increases in peak amplitude. Most of NSW is projected to experience about 20 more heatwave days a year in the far future than in the present climate. In many locations this is more than a doubling of the current number of heatwave days.

\section{ACKNOWLEDGMENTS}

Funding came from the NSW Office of Environment and Heritage including the NSW/ACT Regional Climate Modelling Project (NARCliM). The modelling work was undertaken on the NCI high performance computers in Canberra, Australia, supported by the Australian Commonwealth Government.

\section{REFERENCES}

Coates, L., Haynes, K., O’Brien, J., McAneney, J., de Oliveira, F.D. (2014). Exploring 167 years of vulnerability: An examination of extreme heat events in Australia 1844-2010. Environ. Sci. Policy 42, 3344. doi:10.1016/j.envsci.2014.05.003

Evans, J.P., Ji, F., Abramowitz, G., Ekström, M. (2013). Optimally choosing small ensemble members to produce robust climate simulations. Environ. Res. Lett. 8, 044050. doi:10.1088/1748-9326/8/4/044050

Evans, J.P., Ji, F., Lee, C., Smith, P., Argüeso, D., Fita, L. (2014). Design of a regional climate modelling projection ensemble experiment - NARCliM. Geosci Model Dev 7, 621-629. doi:10.5194/gmd-7-6212014

IPCC (2013). Climate Change 2013: The Physical Science Basis. Contribution of Working Group I to the Fifth Assessment Report of the Intergovernmental Panel on Climate Change. Cambridge University Press, Cambridge, United Kingdom and New York, NY, USA.

Jones, D.A., Wang, W., Fawcett, R. (2009). High-quality spatial climate data-sets for Australia. Aust. Meteorol. Mag. 58, 233-248.

Langlois, N., Herbst, J., Mason, K., Nairn, J., Byard, R.W. (2013). Using the Excess Heat Factor (EHF) to predict the risk of heat related deaths. J. Forensic Leg. Med. 20, 408-411. doi:10.1016/j.jflm.2012.12.005

Nairn, J.R., Fawcett, R.J.B. (2014). The Excess Heat Factor: A Metric for Heatwave Intensity and Its Use in Classifying Heatwave Severity. Int. J. Environ. Res. Public. Health 12, $227-253$. doi:10.3390/ijerph120100227

Perkins, S.E., Alexander, L.V. (2012). On the Measurement of Heat Waves. J. Clim. 26, 4500-4517. doi:10.1175/JCLI-D-12-00383.1 